\title{
Open Government Data: A Stage Model
}

\author{
Evangelos Kalampokis ${ }^{1,2}$, Efthimios Tambouris ${ }^{1,2}$, and Konstantinos Tarabanis ${ }^{1,2}$ \\ ${ }^{1}$ Informatics and Telematics Institute, Centre for Research and Technology Hellas, Greece \\ ${ }^{2}$ University of Macedonia, Thessaloniki, Greece \\ \{ekal, tambouris, kat\}@uom.gr
}

\begin{abstract}
Public sector information constitutes a valuable primary material for added-value services and products, which however remains unexploited. Recently, Open Government Data (OGD) initiatives emerged worldwide aiming to make public data freely available to everyone, without limiting restrictions. Despite its potential however there is currently a lack of roadmaps, guidelines and benchmarking frameworks to drive and measure OGD progress. This is particularly true as proposed stage models for measuring eGovernment progress focus on services and do not sufficiently consider data. In this paper, we capitalize on literature on eGovernment stage models and OGD initiatives to propose a stage model for OGD. The proposed model has two main dimensions, namely organizational \& technological complexity and added value for data consumers. We anticipate the proposed model will open up a scientific discussion on OGD stage models and will be used by practitioners for constructing roadmaps and for benchmarking just like the European Union stage model is currently used for measuring public service online sophistication.
\end{abstract}

Keywords: Stage model, open data, eGovernment, data integration.

\section{Introduction}

Public sector produces, collects, maintains and disseminates a wealth of information. Governments all over the world realize that "within the exercise of its public tasks, the public sector collects, processes and disseminates huge quantities of information" [1]. Examples include maps and satellite images, legislation and case-law, statistics and company, population and patent registers [2]. In Europe, "public bodies are by far the largest producers of information" [3].

The availability of this information (government data onwards) in easily accessible digital format makes it possible to re-use it and combine it with other digital content to create new added-value services and products. Examples include navigation services, real-time traffic information, weather forecasts e.g. sent directly to mobile phones and credit rating services [2]. It is widely recognized that such data-based, added value services and products increase government transparency, improve public administration's function, contribute to economic growth and provide social value to citizens [4] [5]. They generate new businesses and jobs and give consumers more choice and more value for money [2].

The value of the government data market in the European Union (EU) is estimated having a mean value around 27 billion Euros [5]. More than a decade ago the 
European Commission recognised the potential of exploiting this information to boost economic activity and job creation [3] [6] [7]. At the political level, the European Parliament and the Council have launched a Directive on the re-use of government data [1]. Therefore, government data constitutes a valuable asset for both society and economy and as a result governments have a mandate to enable and facilitate data consumption and exploitation by both citizens and businesses.

Nevertheless, problems on government data re-use such as lack of information on available data [2] or the need to bring some order to the mass of data produced [8] still exist. A recent evaluation of the European Directive underpins a number of barriers towards the full exploitation of government data [2]. Things seems better in USA where re-use is strongly encouraged [2] however even there the potential of government data has not been fully exploited.

This situation seems to change in the last couple of years, where a large number of governments worldwide started to massively make data available on the Web. This Open Government Data (OGD) movement follows the Open Data philosophy suggesting making data freely available to everyone, without limiting restrictions. One of the main tenets of OGD is that government provides data and then private parties built added value products and services that provide interactive access for the public [9]. A recent study however has shown that current OGD initiatives employ different approaches for providing data and exhibit important limitations such as data duplication [10].

It is therefore evident there is a lack of roadmap guidelines to set clear objectives for next steps and benchmarks and measure progress. This is particularly true, as the various stage models developed during the last decade for measuring the progress of eGovernment development do not seem appropriate for OGD. Indeed, these models often consider online information provision as the lowest stage in eGovernment development while the higher stages aim at enabling online transaction and providing sophisticated online services through governments transformation [11], [12], [13] and [14]. Apparently, the existing eGovernment stage models are not capable of describing the increasing OGD movement.

The objective of the paper is to supplement the existing eGovernment stage models by introducing an $O G D$ stage model aiming at (a) providing a roadmap for open government data re-use and (b) enabling evaluation of relevant initiatives' sophistication. To this end, we review existing eGovernment models in order to identify how they deal with government data provision and also OGD literature in order to identify characteristics and limitations of current initiatives.

The remaining of this paper is organized as follows. In section 2 we outline important issues that should be taken into consideration in government data provision. Section 3 presents the review of eGovernment stage models as well of OGD models. In section 4 the OGD stage model is presented. Finally, in section 5 conclusions are drawn and future work is presented.

\section{Considerations for Government Data Re-use on the Web}

As already mentioned, the Open Government Data (OGD) movement aims to unlock public information to enable re-using it and combining it with other digital content to create new added-value services and products. However, there are a number of important 
challenges for realizing this aim. These include legal issues, such as those relevant to data privacy and protection, cultural issues, e.g. related to politicians and public servants, and socio-technical issues related to organizational and technological challenges. In this paper, we concentrate on the latter issues particularly those related to enable re-using government data including combining it with other open data on the Web.

Government data is produced, collected, stored and disseminated by public agencies. Each agency manages data according to its mandate. The issues related to re-use of government data would be much easier resolved from an organizational perspective, if public agencies (a) were totally independent from each other and (b) were managing different data from those managed by other agencies. However, in the public sector none of these two conditions is true.

On the contrary, agencies formulate hierarchical structures that contain a number of administrative levels. Thus, agencies have in their responsibility and sometimes control other agencies, i.e. those belonging to a lower administration level. In addition, the public sector is organized in functional areas, such as education, health etc. This decentralized organizational structure of the public sector suggests that in certain cases public agencies in different administration levels and different functional areas produce, maintain and possibly disseminate similar data i.e. data about similar real-world objects or problems. This situation results in a number of challenges regarding data quality. In particular, it is possible that the disseminated data is incomplete, controversial and/or obsolete.

At the same time, the Web is moving from a model of connected documents to a model based on the connections between real-world objects and data describing these objects [15]. In this context, a number of Web sites and platforms opened up recently their data. Examples include Facebook's Graph API ${ }^{1}$, Twitter's RESTful API ${ }^{2}$, the semantically enabled Google's Rich Snippets ${ }^{3}$ and also the Linking Open Data project $^{4}$, which realized the provision of Linked Data from a number of Web sources such as Wikipedia. Linked Data aims to extend the Web with a data commons by creating typed links between data from different sources [16].

Government data is part of this ongoing evolution of the Web and thus it should be combined and integrated with other open data on the Web in order to allow for added value services. To this end, both governments and private sector are expected to develop the necessary technological infrastructure and establish the appropriate organizational processes. Governments could be involved and play an important role in this process because they own the data and thus can understand it better than third parties.

\section{Related Work}

In this section we review eGovernment stage models as well as Open Government Data (OGD) models. We analyze all proposed dimensions and stages but particularly

\footnotetext{
1 http://developers.facebook.com/docs/reference/api/

2 http://dev.twitter.com/doc

3 http: //googlewebmastercentral.blogspot.com/2009/05/ introducing-rich-snippets.html

4 http: / / www.w3 .org/wiki/SweoIG/TaskForces/CommunityProjects / LinkingopenData
} 
concentrate on organizational \& technological complexity and data integration considerations due to the analysis presented in the previous section.

\section{1 eGovernment Stage Models}

During the last decade, a number of models and schemes have been suggested by international organizations, consulting firms and researchers in order to provide a roadmap for eGovernment development and to enable evaluation of relevant initiatives. The European Union [17] proposed a five-stage maturity model in order to enable benchmark and rate "governments' service delivery processes". The stages included in the model, which are described based on maturity and sophistication, are the following: information, one-way interaction, two-way interaction, transaction and finally targetisation. Layne and Lee [11] in order to describe different stages of eGovernment development introduced a "stage of growth model for fully functional eGovernment". This model comprises four stages, namely cataloguing, transaction, vertical integration and horizontal integration. These stages are explained in terms of organizational and technological complexity as well as different levels of integration. Deloitte Research [18] described the stages that a government will pass as electronic service delivery evolves. The aim of this model was to identify the key issues governments need to resolve to make this moving successful. The proposed model includes six stages, namely information publishing/dissemination, official two-way transactions, multi-purpose portals, portal personalization, clustering of common services, full integration and enterprise transformation. Deloitte Research described the model using two axes: the eminence of web-based applications and the degree of enterprise transformation. eGovernment transformation was described by West [19] using four stages, namely the bill board stage, the partial service delivery stage, the portal stage, including fully executable and integrated service delivery, and interactive democracy including public outreach and accountability enhancing features. West's aim was to provide a tool to researchers to determine an agency's progress based on how far along they are at incorporating various web site features. To this end, he studied more than 1800 government websites in the United States and carried out a survey involving chief information officers in different state and federal agencies. Based on Layne and Lee's model, Andersen and Henriksen [20] proposed a progressive growth model for eGovernment. Here, the key dimensions are the degree of activity-centric websites and processing of end-users information and service requests. The first phase of the model is cultivation, which shelters horizontal and vertical integration within government, limited use of front-end systems for customer services and adoption and use of Intranet within government. The next phase is extension that involves extensive use of intranet and adoption of personalized Web user interface for customer processes. Phase three is maturity where the organization matures and abandons the use of the intranet, have transparent processes, and offers personalized Web interface for processing of customer requests. The last phase is revolution characterized by data mobility across organizations, application mobility across vendors, and ownership to data transferred to customers. In this phase, the employees' actions can be traced through the Internet and there is information available online about progress in, for example, case handling. The Center for Democracy \& Technology [21] suggested a model to divide the process of eGovernment implementation into three independent phases. These phases do not need one phase be completed before another can begin. The first one is publish, i.e. 
using ICT to expand access to government information, the second is interact, i.e. broadening civic participation in government, and the last one is transact, i.e. making government services available online.

Table 1. Review of eGovernment stage models

\begin{tabular}{|c|c|c|}
\hline & Dimensions & Stages \\
\hline $\begin{array}{l}\text { Andersen and } \\
\text { Henriksen [20] }\end{array}$ & $\begin{array}{l}\text { Degree of activity-centric } \\
\text { websites and processing of } \\
\text { the end-users information } \\
\text { and service requests }\end{array}$ & $\begin{array}{l}\text { Cultivation, extension, maturity and } \\
\text { revolution. }\end{array}$ \\
\hline Center for & $\mathrm{n} / \mathrm{a}$ & Publish, interact and transact. \\
\hline $\begin{array}{l}\text { Democracy \& } \\
\text { Technology } 211]\end{array}$ & & \\
\hline $\begin{array}{l}\text { Deloitte Research } \\
\text { [18] }\end{array}$ & $\begin{array}{l}\text { Eminence of web-based } \\
\text { applications and the degree } \\
\text { of enterprise transformation }\end{array}$ & $\begin{array}{l}\text { Information publishing, two-way } \\
\text { transactions, multi-purpose portals, portal } \\
\text { personalization, clustering of common } \\
\text { services, full integration and enterprise } \\
\text { transformation. }\end{array}$ \\
\hline $\begin{array}{l}\text { European Union } \\
{[17]}\end{array}$ & Maturity and sophistication & $\begin{array}{l}\text { Information, one-way interaction, two-way } \\
\text { interaction, transaction and targetisation. }\end{array}$ \\
\hline $\begin{array}{l}\text { Layne and Lee } \\
{[11]}\end{array}$ & $\begin{array}{l}\text { Organization }- \text { technological } \\
\text { complexity and different } \\
\text { levels of integration }\end{array}$ & $\begin{array}{l}\text { Cataloguing, transaction, vertical } \\
\text { integration and horizontal integration. }\end{array}$ \\
\hline Lee [14] & $\begin{array}{l}\text { Citizen/service and } \\
\text { operation/technology }\end{array}$ & $\begin{array}{l}\text { Presenting, assimilating, reforming, } \\
\text { morphing and eGovernance }\end{array}$ \\
\hline $\begin{array}{l}\text { Siau and Long } \\
\text { [13] }\end{array}$ & $\begin{array}{l}\text { Time/complexity/integration } \\
\text { and benefits/costs }\end{array}$ & $\begin{array}{l}\text { Web presence, interaction, transaction, } \\
\text { transformation and eDemocracy. }\end{array}$ \\
\hline West [19] & $\mathrm{n} / \mathrm{a}$ & $\begin{array}{l}\text { Bill board, partial service delivery, portal } \\
\text { stage (with fully executable and integrated } \\
\text { service delivery) and interactive } \\
\text { democracy. }\end{array}$ \\
\hline
\end{tabular}

In addition, work has been also carried out aiming to compare and synthesize eGovernment models. For example, Siau and Long [13] developed a five-stage model to synthesize eGovernment stage models of that time so that to create a common frame of reference for researchers and practitioners in the area. This model is described in terms of time, complexity and integration as well as benefits and costs. More specifically, according to this model time spending, system complexity, integration, benefits and costs all increase with the advancement of eGovernment. The model proposed consists of five stages, namely web presence, interaction, transaction, transformation and eDemocracy. Finally, Lee [14] also compared existing eGovernment development models in order to identify a common frame of reference across different stage model. This framework comprises two dimensions, namely citizen/service perspective and operation/technology perspective and five stages, namely presenting, assimilating, reforming, morphing and eGovernance. 
Table 1 summarizes the review of the existing eGovernment stage models. As regards the dimensions utilized for describing the model the majority of the works include dimensions related to socio-technical issues such as technological complexity, organizational complexity, enterprise transformation etc. As regards the description of data provision the majority of these models consider it as the first stage in eGovernment development.

\subsection{Open Government Data Models}

Recently, Kalampokis et al. [10] proposed a classification scheme for Open Government Data (OGD) and identified four generic classes that could describe all relevant initiatives. To this end, the authors analyzed 24 recently launched OGD initiatives around the globe and studied relevant practical models such as the five-star model of Tim Berners-Lee [22] and W3C's three step model [23]. This study revealed some interesting characteristics of OGD initiatives with regards to the employed technological approaches as well some limitations that current initiatives present.

In particular, current OGD initiatives use the following main technological approaches for publishing their data:

- Making data available of the Web as downloadable files in well-known formats such as PDF, Excel, CSV, KML, XML, JSON etc

- Making data available of the Web as Linked Data through RESTful APIs and/or SPARQL search interfaces.

The majority of the existing initiatives fall into the first technological approach while only three to the second, namely Data.gov.uk, Data.gov and "Catálogo de Datos de Asturias".

In addition, the study concluded in some limitations that many current OGD initiatives present mainly because of the followed organizational approach. In particular, in 18 out of the 24 initiatives the OGD portal re-publishes data sets that a public agency has already published in a different place on the Web. This approach results in data duplication and in problems related to maintainability and accuracy of the provided data. Some initiatives try to overcome this issue utilizing an indirect approach for providing data (i.e. they publish references to the actual data sets published by the different agencies in a decentralized way) however this approach impedes data integration.

\section{The Stage Model}

The proposed stage model comprises four stages as depicted in Fig. 1. The aim of the model is two-fold: first to provide a roadmap for open government data re-use and second to enable evaluation of relevant initiatives' sophistication. In Fig. 1, the vertical axis presents the technological and organization complexity that is involved in the provision of the data while the horizontal axis presents the capability of developing added value services based on the provided data. In this section, we describe the four stages of the proposed model. 


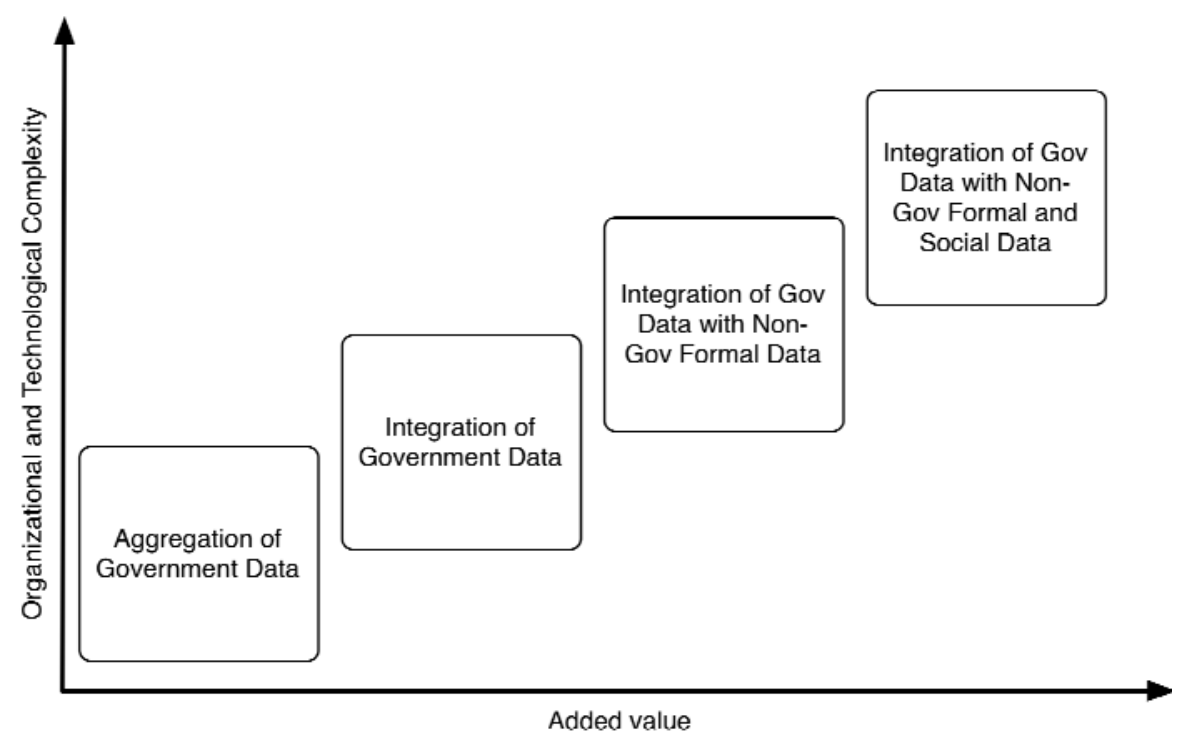

Fig. 1. The Open Government Data Stage Model

\subsection{Stage 1: Aggregation of Government Data}

This stage includes opening up data, publishing data online for others to re-use and, possibly, aggregating data provided by different sources. The main concern of public agencies in this stage is to easily and quickly make their data available online. Different agencies can publish their data employing different technological solutions and following different implementation details. This stage may also include data aggregation in a single website like the recently launched OGD portals. We use the term aggregation here to indicate that data is simply gathered and provided together from a single point of access.

In this stage, public agencies have to overcome a number of organizational, cultural and legislative barriers. In the case of European Union, the ultimate goal of the Directive on public sector information re-use is for all member States to overcome these barriers and hence provide their data online for anyone to re-use.

From an organizational perspective, open data at this stage can be provided in one of the following ways:

- The public agency publishes the data sets on its website or on the website of a higher-level agency.

- The public agency forwards the data set to an OGD portal that publishes the data.

- The public agency publishes the data sets and the OGD portal provides links to the actual data sets along with metadata.

From a technological perspective, the following approaches are possible according to the analysis presented in sub-section 3.2: 
- Publish downloadable files in well-known formats such as CSV, XML, KML etc.

- Publish data using the linked data paradigm but without caring about linking to other data sets.

The main benefit of this first stage is that the public gains access to a wealth of valuable data. This data can be used for the development of new added value services. However, at this stage, governments do not consider a number of limitations that could impede data use and re-use. Actually, data is available as provided by agencies and thus it is not possible to automatically search across data provided by different agencies or combine them in order to create value-added services and products. According to the analysis presented in Section 2, these limitations are related to data duplication and data freshness, data formats that facilitate re-use, complete metadata, linking to other data sets etc.

As a result, at this stage data consumers need to be involved in a time and effort consuming process in order to overcome these limitations and use the provided data. This process could include the identification of all sources that provide data related to a specific real-world problem, assess the accuracy of the data, fuse the identified data sets, transform the data to the appropriate format, identify other data sets that could add value to the solution and integrate them with the initial ones.

Based on [10], in which a significant number of OGD initiatives were analyzed, we deem that the majority of the existing OGD initiatives fall into this stage. An indicative example of government data provision in this stage can be given by Data.gov.uk where data on criminal statistics is provided both in the Ministry of Justice website ${ }^{5}$ and the central access point ${ }^{6}$ where in the latter an outdated version of the data exists.

\subsection{Stage 2: Integration of Government Data}

This stage includes government data integration across public administration. The analysis of Section 2 presented a number of government data provision challenges that emerge from the decentralized structure of public administration. These challenges emerge when different agencies in different administrative levels and functional areas provide data about the same real-world problem since this data can be incomplete, controversial or obsolete.

The most important benefit of this stage is the provision of a unified view of government data that comes from different sources. In addition, it is expected that integrated government data will be complete and concise: complete suggests no specific object is forgotten; concise suggests no object is represented twice and data is without contradiction.

Government data integration is a very challenging task that includes significant technological and organizational issues. As regards the technological issues, governments should provide their data in specific formats that enable and facilitate integration on the Web. At the moment, Linked Data seems to be the most promising approach towards this direction. Thereafter, governments should decide on the architectural approach to follow (e.g. central repositories or federated queries). Other

\footnotetext{
${ }^{5}$ http: / / www.justice.gov.uk/publications/criminalannual.htm

${ }^{6}$ http://data.gov.uk/data set/criminal-statistics-england-and-wales
} 
technological issues involved in this process are data schemas standardization, identifiers standardization, etc. With regards to the organizational issues, governments should establish business processes that prevent data re-publishing from different agencies, ensure in-time publishing and enhance data accuracy. Decentralized data provision could be a solution towards this direction i.e. every public agency to disseminate only the data that has the mandate to manage.

This type of integration will enable data consumers to execute more complex queries on top of the integrated data. A simple question that could be easily answered at this stage would be "Which governmental points of interest are located on a specific area?"

Although the final goal of this stage is to provide integrated government data across every public agency, it is more possible partial integration to take place in the beginning. These initial efforts can be developed around real-world objects or specific real-world problem related queries. We can deem that this is the case in Data.gov.uk where partial integrated data is provided around specific real-world object such as schools, bus stops, members of parliament, geo-locations etc. In these initiatives linked data technologies are employed and also links have been established between data sets provided by different public agencies such as Ordnance Survey, the Ministry of Education and the London Gazette.

\subsection{Stage 3: Integration of Gov Data with Non-Gov Formal Data}

Government data can be characterized as formal as it is published by a highly trustworthy source. Data consumers assume that data published by governments is always accurate and reliable. However, many non-governmental sources also provide formal data on the Web in structured formats that allow for re-use. In this category we could encompass DBpedia ${ }^{7}$, which is the linked data version of Wikipedia, and Data.nytimes ${ }^{8}$, which is the New York Times' linked open data set. Although the former is a social platform, users' participation ensures that the provided information is objective, accurate and unbiased. This sort of sources provides data about realworld things such as organizations, people and locations as well as subject descriptors such as "greenhouse gas emissions".

The integration of government data with this non-government formal data defines the next stage of the proposed model. This type of integration will enable the provision of richer information to data consumers and will allow for more complex queries answering. A simple use case that will be enabled by this stage could include the identification of news posts that refer to public agencies or politicians connected to high expenditures in the governmental budget reports.

The implementation of this stage increases both organizational and technological complexity that should be overcome by governments and third parties. As regards the former, possible conceptual integration points between government and nongovernment formal data should be identified. These integration points will define use cases that could add value to data consumers. Thereafter, relevant government data sets and sources of non-government formal data should be identified and the required

\footnotetext{
${ }^{7}$ http : / / dbpedia.org

${ }^{8}$ http : / / data.nytimes. com
} 
technological and organizational connections that will enable data integration should be established. Taking into account that Linked Data is the most advanced technological approach in government data provision, the technological requirements of this stage would be the establishment and maintenance of links between government and non-government data sets. In addition, richer metadata should be included in order to describe these links and these data sources.

\subsection{Stage 4: Integration of Gov Data with Non-Gov Formal and Social Data}

The final stage of the proposed model covers the integration of government data with not only non-government formal data but also social data on the Web. We define social data as data that is created and voluntarily shared by citizens through social media platforms such as Twitter and Facebook. This sort of data is differentiated from government data and non-government formal data because it mainly communicates personal opinions, beliefs and preferences.

This type of integration will allow for new innovative services in which government data will provide a context of interpretation for social data. In particular, it will enable governments to consider citizens' opinion expressed through social media in governmental decision-making processes; it will further allow citizens to deliberate in social media about public administration related real-world things such as laws and public agencies in a more explicit manner.

For example, at this stage governments and citizens will be able to answer questions such as "What is the opinion of citizens affected by a specific law about this law?" In addition, governments will be able to understand public sentiment on specific decisions by analyzing integrated government and social data and thus take corrective actions that would alleviate the foreseen reactions.

Social data is streamed in large quantities every second, mainly through social networking platforms such as Twitter and Facebook. Taking into account the fact that social data is highly dynamic and unstructured, we understand that this type of integration introduces additional technological and organizational requirements. It should be also noted that we do not expect permanent links to be established between government and social data in this type of integration. Nevertheless, the appropriate mechanisms to allow and facilitate this type of integration should be established.

The additional complexity related to this stage could be better described by a realworld case. A very popular attribute of social data that enables personalization is the location from which a message is published online. This attribute could be the "joint point" for different government and social data sets. However, the format and granularity of data describing locations can vary between different data sets. For example, although Twitter adds the longitude and latitude of a point to tweets posted by mobile applications, Ordnance Survey in the UK does not provide a service for mapping a specific point to an administrative area in order a linking between these to representations of a geo-spatial object to be enabled.

\section{Conclusions and Future Work}

The public sector produces, collects, processes and disseminates a large amount of data. These can be re-used and integrated to create new value-added services and 
products with potentially significant impact in global economy. Recently, Open Government Data (OGD) initiatives emerged worldwide aiming to unlock public sector data, aggregate them and make them available through one-stop access points. These initiatives however are lacking a roadmap to provide guidance and an evaluation framework to assess progress.

In this paper we present a stage model for OGD. The model capitalizes on stage models proposed to measure the development of eGovernment. Unlike these models however where focus is on service provision the proposed model's focus is on data integration. The model consists of two main dimensions, namely organizational \& technological complexity and added value for data consumers. The model includes four stages, namely aggregation of government data, integration of government data, integration of government data with non-government formal data and integration of government data with non-government formal and social data.

The proposed model can be used by researchers to further study OGD roadmaps and evaluation frameworks. It can be also used by practitioners as both a roadmap and a framework to evaluate progress.

Future work in the area is envisaged in a number of directions. First, current OGD initiatives will be thoroughly studied to identify important data sets for each stage of the model to be identified. This will enable better understanding the current state of play in the area and to set future targets. These important data sets could be also applied in the same sense that the European Union defined "20 basic public services" to measure eGovernment's sophistication. Second, each stage will be thoroughly studied in terms of organizational barriers and technological solutions. Here, we envisage building one or more reference IT architectures and prototype implementations for each stage.

Acknowledgments. The work presented in the paper is partly funded by the EU under Grant No. 238900 (Rural Inclusion - CIP-ICT-PSP).

\section{References}

1. European Commission: Directive 2003/98/EC of the European Parliament and of the Council of 17 November 2003 on the re-use of public sector information (2003)

2. Communication from the Commission to the European Parliament, the Council, the European Economic and Social Committee and the Committee of the Regions - Re-use of Public Sector Information: review of Directive 2003/98/EC - [SEC, 597] (2009)

3. eContent: Commercial exploitation of Europe's public sector information (2000)

4. Newberry, D., Bently, L., Pollock, R.: Models of Public Sector Information Provision via Trading Funds (2008), http: / /www. berr.gov.uk/files/file45136.pdf

5. Dekkers, M., Polman, F., Velde, R., de Vries, M.: MEPSIR: Measuring European Public Sector Information Resources. Final Report of Study on Exploitation of public sector information - benchmarking of EU framework conditions (2006),

http: / / ec.europa.eu/information_society/policy/psi/docs/pdfs / mepsir/final_report.pdf

6. European Commission: Public Sector Information: A Key Resource for Europe, COM, 585 (1998) 
7. eEurope2002: Creating a EU Framework for the Exploitation of Public Sector Information, COM, 607 final (2001)

8. The Irish Public Service Metadata Standard, IPSMS (2002), http: / / www.gov. ie/webstandards/metastandards/intro.html

9. Robinson, D., Yu, H., Zeller, W.P., Feltern, E.W.: Government Data and the Invisible Hand Yale J.L. \& Tech., vol. 11, p. 160 (2009)

10. Kalampokis, E., Tambouris, E., Tarabanis, K.: A Classification Scheme for Open Government Data: Towards Linking Decentralized Data. International Journal of Web Engineering and Technology 6(3), 266-285 (2011)

11. Layne, K., Lee, J.: Developing fully functional E-Government: A four stage model. Government Information Quarterly 18(2), 122-136 (2001)

12. Klievink, B., Janssen, M.: Realizing joined-up government - Dynamic capabilities and stage models for transformation. Government Information Quarterly 26(2), 275-284 (2009)

13. Siau, K., Long, Y.: Synthesizing e-government stage models - a meta-synthesis based on meta-ethnography approach. Industrial Management \& Data Systems 105(4), 443-458 (2005)

14. Lee, J.: 10 year retrospect on stage models of e-Government: A qualitative meta-synthesis. Government Information Quarterly 27(3), 220-230 (2010)

15. Berners-Lee, T.: Giant Global Graph (2007), http: / /dig.csail.mit. edu/breadcrumbs/node/215

16. Bizer, C., Heath, T., Berners-Lee, T.: Linked Data-The Story So Far. Special Issue on Linked Data, International Journal on Semantic Web and Information Systems 5(3), 1-22 (2009)

17. European Commission Directorate General for Information Society and Media: Smarter, Faster, Better eGovernment. 8th eGovernment Benchmark Measurement (2009)

18. Deloitte Research: At the dawn of E-Government: The citizen as customer (2000)

19. West, D.M.: E-Government and the transformation of service delivery and citizen attitudes. Public Administration Review 64(1), 15 (2004)

20. Andersen, K.V., Henriksen, H.Z.: E-government maturity models: Extension of the Layne and Lee model. Government Information Quarterly 23, 236-248 (2006)

21. Center for Democracy \& Technology, The e-Government handbook for developing countries: A project of InfoDev and the Center for Democracy \& Technology. Center for Democracy \& Technology, CDT, Washington, D.C (2002)

22. Berners-Lee, T.: Design issues: Linked data (2006), updated (2010), http: / / www .w3 .org/DesignIssues / LinkedData.html

23. W3C: Publishing Open Government Data. W3C Working draft (2009), http://www.w3.org/TR/gov-data/ 